\title{
25 Research Soure \\ Sex Differences in Clinical Characteristics and Risk Factors for Disease Severity of Hospitalized Patients with COVID-19 in Beijing
}

Jingjing Wang

Capital Medical University Affiliated Beijing Ditan Hospital

\section{Yunjuan Su}

Capital Medical University Affiliated Beijing Ditan Hospital

Qi Wang

Capital Medical University Affiliated Beijing Ditan Hospital

\section{Ying Cao}

Capital Medical University Affiliated Beijing Ditan Hospital

\section{Aibin Wang}

Capital Medical University Affiliated Beijing Ditan Hospital

\section{Rui Ding}

Capital Medical University Affiliated Beijing Ditan Hospital

Wen Xie ( $\nabla$ xiewen6218@163.com )

Beijing Ditan Hospital, Capital Medical University

\section{Research}

Keywords: COVID-19, SARS-CoV-2, sex differences, risk factors, disease severity

Posted Date: September 29th, 2020

DOI: https://doi.org/10.21203/rs.3.rs-76948/v1

License: (1) This work is licensed under a Creative Commons Attribution 4.0 International License. Read Full License 


\section{Abstract}

Background: Recent studies reported that sex differences in patients with coronavirus disease-2019 (COVID-19). However the predictive value of sex differences in disease severity were less studied by previous scholars.

Methods: All adults ( $\geq 18$ years) diagnosed with COVID-19 and admitted to Beijing Ditan Hospital, Capital Medical University (admission date from January 13 to March 19, 2020) were included in samples. Data analyzed in this study included epidemiological, demographic, comorbidities, initial symptoms and signs, laboratory findings, imaging study, disease severity and in-hospital mortality.

Results: A total of 185 inpatients were enrolled in the study, among whom 95 patients are males (51.4\%). The mean age of all patients was 41 years. Based on the hospital record, the duration from symptoms initiation to hospital admission was longer for men than that for women. Moreover, the mean BMI of males was relatively higher compared to females $(25.45 \mathrm{vs} 22.29, \mathrm{p}<.001)$. In addition, the proportion of male patients with CHD, NAFLD, smoking and drinking history was higher than females. During the hospital stay, compared to female patients, male patients were more prone to develop symptoms such as high fever, cough, and chill. Higher levels of AST, CK, CRP and FIB were also observed in male patients. Following this fact, more patients with abnormal CT activities, severe and critical symptoms were developed in male group than females. However, there was no difference in complications and outcome between two groups. By analyzing data comprehensively, we found out that age (analyzed in quartiles, OR: 1.087; 95\% Cl: 1.038-1.139; $p$ <.001) and BMI (OR: 1.250; 95\% Cl: 1.046-1.493; p $=.014$ ) could be used to help predict disease severity.

Conclusions: In this cohort of hospitalized patients in Beijing, male patients developed more clinical symptoms, obtained more abnormal laboratory test results, and showed higher rates in severity of COVID-19. Other than that, the severity of COVID-19 was positively correlated with age and BMI independently.

\section{Introduction}

COVID-19 is an emerging respiratory infectious disease caused by the severe acute respiratory syndrome coronavirus 2 (SARS-CoV-2), and triggered a global pandemic which has not been under control yet ${ }^{[1,2]}$. Even the situation has been curbed in some countries as of July 11, there are still 12,322,395 cases diagnosed and 556,335 deaths confirmed around the world. Previous reports have reported that there existed a sex imbalance based on confirmed cases and case fatality rate of COVID-19 ${ }^{[3]}$. Notably, the roles and significance of sex are often neglected in studies of infectious disease ${ }^{[4]}$. As studied, hormone difference alters the host response to infection disease, and sex-biasing differences influence host pathogen interactions ${ }^{[5]}$. Previous studies have reported that Europe and American had higher percentage of male patients male patients with COVID-19 were far worse than females ${ }^{[6]}$.More than that, male sex, older age, underlying disease such as diabetes, hypertension, obesity, coronary artery disease are risk factors associated with worse outcomes ${ }^{[7]}$. The health status of Beijing residents has reached the level of high-income countries and regions, and the health status of women is better than that of men. Based on recent reports, the prevalence of overweight was the highest in Beijing among Chinese adults published in 2019, the prevalence of overweight was the highest in Beijing ${ }^{[8,9]}$. The differences in the health status of men and women might contribute to the sex differences in COVID-19 and the characteristics of COVID-19 may be different from those of other cities as well. However, sex differences associated with clinical characteristics, severity and mortality of COVID-19 in Beijing have not been well described yet. We summarized the clinical 
characteristics, co-morbid conditions, severity and outcomes of 185 hospitalized patients in order to investigate whether sex bias is associated with the clinical characteristics and early outcomes of the patients who were diagnosed with COVID-19 in Beijing and to assess potential risk factors on patients with severe COVID-19 at admission.

\section{Materials And Methods}

\section{Study population and design}

From January 13, 2019 to March 19, 2020, a total of 185 adults with COVID-19 were diagnosed and admitted if tested positive for respiratory symptoms, showed typical chest imaging findings, and tested positive SARS-CoV-2 test results of pharyngeal swab specimens in Beijing Ditan Hospital. Data collected through the EMR system included baseline demographic information (age, sex, clinical characteristics (body mass index (BMI)), smoking history, alcohol consumption, hypertension, medical records (type 2 diabetes, coronary heart disease(CHD), hypertension (HT), Type 2 diabetes (T2DM), respiratory disease, and nonalcoholic fatty liver disease(NAFLD)),symptoms (fever, headache, fatigue, cough, sore throat, cough, expectoration, Shortness of breath, nausea/vomiting, myalgia/arthralgia, diarrhea), vital signs (indoor air oxygen saturation, the highest temperature, heart rate, blood pressure), laboratory data of the first 24-hours hospital stay (leukocyte count, neutrophil count, lymphocyte count, neutrophil/lymphocyte ratio(NLR), hemoglobin, platelet count, creatinine, and aspartate aminotransferase (AST), alanine aminotransferase (ALT), troponin T, bilirubin, albumin, creatinine inase (CK), lactate dehydrogenase (LDH), d-dimer, fibrinogen, c-reactive protein (CRP) and calcitonin, serum amyloid $A(S A A)$ ), imaging findings (chest computed tomography), clinical complications (acute respiratory distress syndrome (ARDS), acute kidney injury (AKI) or diffuse intravascular coagulation(DIC), septic shock, co-infection, myocardial damage) and final diagnosis including remained in hospital, discharge, death, and re-admission. All data were analyzed independently by three researchers and obtained in accordance with standard biosafety and institutional safety procedures during the observation period of this study. The severity of the patient with COVID19 is determined based on the diagnostic and treatment guideline for SARS-CoV-2 issued by Chinese National Health Committee (version 7) ${ }^{[10]}$.

\section{Statistical Analysis}

The normality of continuous variables' distribution was tested by one-sample Kolmogorov-Smirnov test. Continuous variables with normal distribution were presents as mean \pm standard deviation (SD); non-normal variables were reported as median (interquartile range). Mean of two continuous normally distributed variables were compared using independent samples Student's test; non-normal variables were reported as median (interquartile range [IQR]). Mann-Whitney U test and Kruskal-Wallis test were used, respectively, to compare means of non-normal distributions.

Categorical variables were summarized as numbers and percentages. We made comparisons via analysis of chisquare for categorical variables between males and females. Correlations between severity of COVID-19 and underlying disease (CHD, HT, T2DM, Respiratory disease, NAFLD) were analyzed in terms of the Spearman Pearson correlation coefficient. Multivariable binary logistic regression analyses were used to assess the association among age, sex, BMI, underlying comorbidity (CHD, HT, T2DM, Respiratory disease, NAFLD), history of smoking, alcohol consumption and the dependent variable of severity of disease (general groupandrefractory group). Results of logistic regression are given as the odds ratio (OR) with the $95 \%$ confidence interval (CI). The 
tests with a 2-sided $\mathrm{P}$ value of <.05 was considered as statistically significant. The data were analyzed by SPSS version 16.0 for Windows (SPSS Inc., Chicago, IL, USA).

\section{Results}

\section{Baseline Characteristics For Different Sex Groups}

A total of 185 patients were admitted and initially diagnosed with COVID-19, among whom 95 (51.4\%) were men. The age of all patients ranged from 18 to 92 years with a median of 41 years, furthermore, there is no differences in age between males and females $(p=.914)$. Based on data collected, the mean BMI was higher in males $(25.45$ vs $22.29, \mathrm{p}<.001$ ) and the mean duration from symptoms initiation to hospital admission was longer for men than that for women ( 6 vs $4, p=.042$ ). Considering previous living habits of patients, the number of patients with smoking and drinking history was significantly higher in male patients (specifically smoking: $18.9 \%$ vs $2.2 \%$ and drinking: $28.4 \%$ vs $6.7 \%, p<.001)$. Among all patients, 77 cases $(41.6 \%)$ had one or more following symptoms including but not limited to hypertension (31.2\%), NAFLD (14.6\%), respiratory diseases (9.2\%), diabetes (7.6\%), coronary heart disease (3.2\%). More specifically, the percentages of males with coronary heart disease (6.3\% vs 0$)$ and NAFLD $(20.0 \%$ vs $8.9 \%)$ were significantly higher than females $(p<0.05)$ (Table 1$)$.

Table 1 Baseline Characteristics According to Sex

\begin{tabular}{|c|c|c|c|c|}
\hline Variables & $\begin{array}{l}\text { All Patients }(n= \\
185)\end{array}$ & Man (n= 95) & Woman $(n=90)$ & $\begin{array}{l}\mathrm{P} \\
\text { values }\end{array}$ \\
\hline $\begin{array}{l}\text { Age [IQR, y] } \\
\mathrm{BMI}\left[\mathrm{kg} / \mathrm{m}^{2,}\right]\end{array}$ & $\begin{array}{l}41(32,57) \\
23.94 \pm 4.41(n=132)\end{array}$ & $\begin{array}{l}42(32,54) \\
25.45 \pm 4.40(\mathrm{n}=69)\end{array}$ & $\begin{array}{l}40.5(29.75,57.25) \\
22.29 \pm 3.81(n=63)\end{array}$ & $\begin{array}{l}0.914 \\
<.001\end{array}$ \\
\hline From symptom to & $5(3,8)$ & $6(3,8)$ & $4(3,8)$ & 0.042 \\
\hline $\begin{array}{l}\text { History of smoking [n (\%)] } \\
\text { Alcohol consumption [n (\%)] } \\
\text { Coronary heart disease[n }\end{array}$ & $\begin{array}{l}20(10.8) \\
33(17.8) \\
6(3.20)\end{array}$ & $\begin{array}{l}18(18.9) \\
27(28.4) \\
6(6.30)\end{array}$ & $\begin{array}{l}2(2.2) \\
6(6.7) \\
0(0)\end{array}$ & $\begin{array}{l}<.001 \\
<.001 \\
0.029\end{array}$ \\
\hline $\begin{array}{l}\text { Hypertension [n (\%)] } \\
\text { Non-alcoholic fatty liver } \\
\text { disease [n (\%)] }\end{array}$ & $\begin{array}{l}42(22.70) \\
27(14.60)\end{array}$ & $\begin{array}{l}24(25.30) \\
19(20)\end{array}$ & $\begin{array}{l}18(20.00) \\
8(8.90)\end{array}$ & $\begin{array}{l}0.393 \\
0.032\end{array}$ \\
\hline $\begin{array}{l}\text { Respiratory disease [n (\%)] } \\
\text { Diabetes [n (\%)] }\end{array}$ & $\begin{array}{l}17(9.20) \\
14(7.60)\end{array}$ & $\begin{array}{l}7(7.40) \\
9(9.50)\end{array}$ & $\begin{array}{l}10(11.10) \\
5(5.60)\end{array}$ & $\begin{array}{l}0.378 \\
0.314\end{array}$ \\
\hline
\end{tabular}

\section{Vital Signs And Laboratory Parameters}

All vital signs and laboratory parameters were collected on the day of hospital admission for all patients. The peak temperature measured prior to hospital admission was higher in male patients than females $\left(38.2^{\circ} \mathrm{C} \mathrm{VS}\right.$ $\left.37.65^{\circ} \mathrm{C}, \mathrm{p}=.008\right)$. Moreover, the medians of SBP, DBP, and MAP in males were higher than in females $(p<.05)$. There was no significant difference in heart rate and respiratory rate between male and female patients. The most common symptoms observed onset were fever (74.6\%), cough (56.2\%), fatigue (35.7\%), expectoration (29.7\%), myalgia/arthralgia (28.1\%), sore throat (20\%), and chills (19.5\%). Furthermore, several less common symptoms such as headache (18.4\%), diarrhea (9.2\%), nausea, and vomiting (5.4\%) were also observed. Of the 185 patients, 138 patients (74.6\%) had two or more symptoms concurrently. Among all the listed symptoms, the percentages of patients with fever $\left(T \geq 38^{\circ} \mathrm{C}, 60.0 \%\right.$ vs $\left.44.4 \%\right)$ ), cough $(65.3 \%$ vs $46.7 \%)$ and chills $(25.3 \%$ vs $13.3 \%)$ were significantly higher in male group than females $(p<.05)$ (Table 2). Although leukocyte count, neutrophil count, lymphocyte count did not differ between two groups $(p>.05)$, the platelet count was significantly lower in male group than that in female group $(P<.001)$. However, no sex differences was observed in lymphopenia and 
thrombocytopenia $(p>$.05). In addition, there were numerous factors showed significant higher levels in males than females including levels of $A L T, C K, C R P(P<.001, P=.006, P=.008$ respectively). Of note, FIB, another acute response protein, was also higher in male patients than that in female patients $(p=.033)($ Table 3$)$.

Table 2 Vital Signs and specified Initial Symptoms

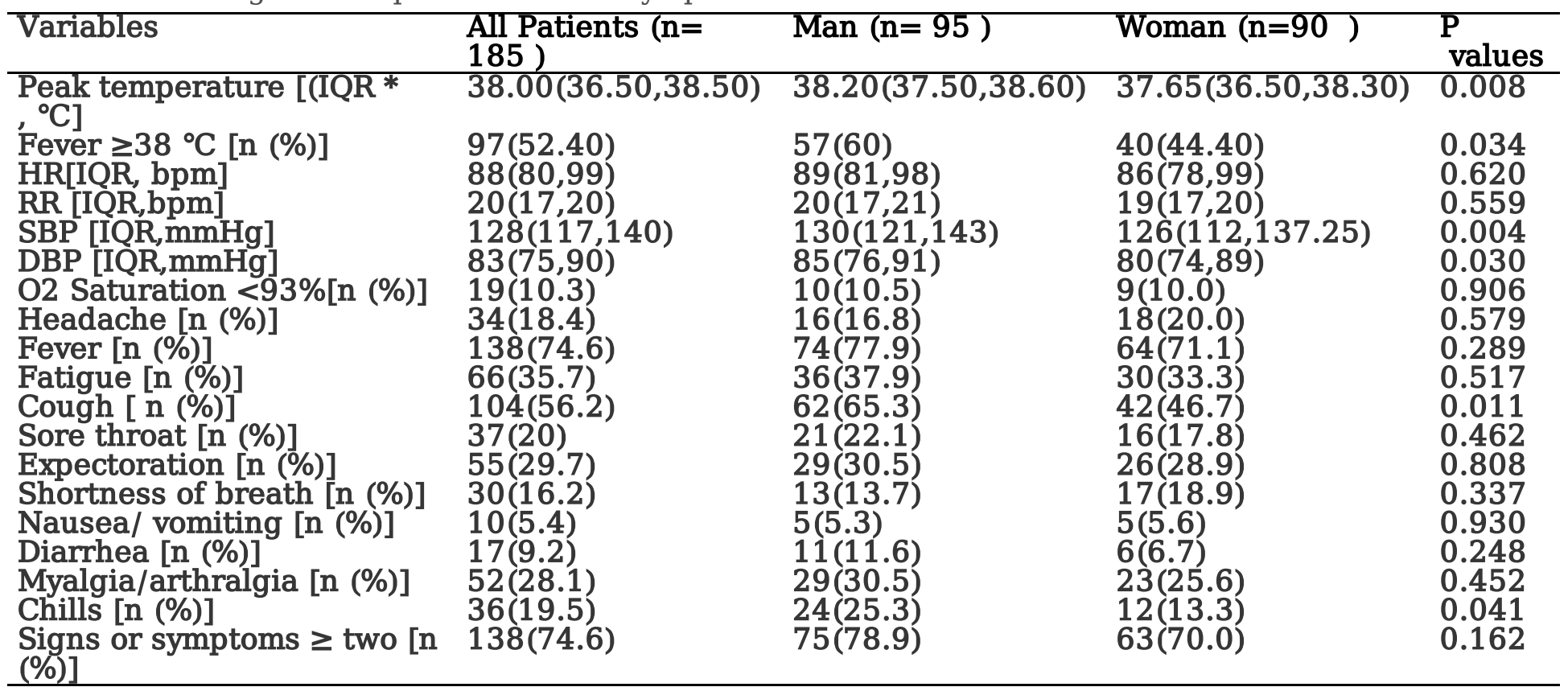

* The peak temperature was measured prior to hospital admission.

Table 3 Laboratory Findings on Admission to Hospital 


\begin{tabular}{|c|c|c|c|c|}
\hline Variables & $\begin{array}{l}\text { All Patients (n= } \\
185 \text { ) }\end{array}$ & $\operatorname{Man}(n=95)$ & Woman $(\mathrm{n}=90)$ & $\begin{array}{l}\mathrm{P} \\
\text { values }\end{array}$ \\
\hline Leukocyte $\left[\times 10^{9} / 1,\right]$ & $5.36 \pm 2.36$ & $5.40 \pm 2.10$ & $5.32 \pm 2.60$ & 0.805 \\
\hline $\begin{array}{l}\text { lymphocyte count }\left[\times 10^{9} / 1\right. \\
,]\end{array}$ & $1.37 \pm 0.61$ & $1.31 \pm 0.57$ & $1.44 \pm 0.65$ & 0.169 \\
\hline $\mathrm{NLR}^{\$}[\mathrm{IQR})$ & $2.50(1.63,3.58)$ & $2.62(1.78,4,07)$ & $2.41(1.37,3.36)$ & 0.110 \\
\hline Haemoglobin $[\mathrm{g} / \mathrm{L}]$, & $140.61 \pm 17.22$ & $149.85 \pm 15.24$ & $130.86 \pm 13.41$ & $<.001$ \\
\hline $\begin{array}{l}\text { Lymphopenia*[n (\%)] } \\
\text { Thrombocytopenia\# [n } \\
\text { (\%)] }\end{array}$ & $\begin{array}{l}123(66.5) \\
39(21.1)\end{array}$ & $\begin{array}{l}67(70.5) \\
25(26.3)\end{array}$ & $\begin{array}{l}56(62.2) \\
14(15.6)\end{array}$ & $\begin{array}{l}0.232 \\
0.073\end{array}$ \\
\hline blood platelet count[IQR,- & $197(154,242)$ & $176(147,225)$ & $223(172,263.25)$ & $<.001$ \\
\hline $\begin{array}{l}\text { Sodium }[\mathrm{IQR},-\mathrm{mmol} / \mathrm{L}] \\
\text { Potassium }[\mathrm{mmol} / \mathrm{L}, \mathrm{IQR}] \\
\text { Creatinine } \geq 133\end{array}$ & $\begin{array}{l}139.1(137.0,140.6) \\
3.71(3.52,4.00) \\
3(1.6)\end{array}$ & $\begin{array}{l}138.1(136.1,140.5) \\
3.8(3.58,4.00) \\
1(1.1)\end{array}$ & $\begin{array}{l}139.9(138.65,141.15) \\
3.7(3.45,3.95) \\
2(2.2)\end{array}$ & $\begin{array}{l}0.001 \\
0.027 \\
0.613\end{array}$ \\
\hline $\begin{array}{l}(\mu \mathrm{mol} / \mathrm{L})[\mathrm{n}(\%)] \\
\text { Aspartate } \\
\text { aminotransferase >40 } \\
\mathrm{U} / \mathrm{L}(\mathrm{n}=176)[\mathrm{n}(\%)]\end{array}$ & $28(15.9)$ & $19(20.4)$ & $9(10.8)$ & 0.083 \\
\hline $\begin{array}{l}\text { Alanine aminotransferase } \\
>40 \mathrm{U} / \mathrm{L}[\mathrm{n}(\%)]\end{array}$ & $36(19.5)$ & $29(30.5)$ & $7(7.8)$ & $<.001$ \\
\hline $\begin{array}{l}\text { Total bilirubin } \geq 17.1 \\
\text { umol/L(n=175) [n (\%)] }\end{array}$ & $22(12.5)$ & $13(14)$ & $9(10.8)$ & 0.530 \\
\hline $\begin{array}{l}\text { Albumin [IQR,g/L] } \\
\text { Creatinine kinase } \geq 200 \\
\text { U/L[n (\%)] }\end{array}$ & $\begin{array}{l}42.4(38.75,45.45) \\
23(12.4)\end{array}$ & $\begin{array}{l}42.4(38,46.30) \\
18(18.9)\end{array}$ & $\begin{array}{l}42.2(39.5,45.2) \\
5(5.6)\end{array}$ & $\begin{array}{l}0.661 \\
0.006\end{array}$ \\
\hline $\begin{array}{l}\text { C-reactive protein level } \geq \\
10 \mathrm{mg} / \mathrm{L}(\mathrm{n}=182)[\mathrm{n}(\%)]\end{array}$ & $74(40.7)$ & $47(50)$ & $27(30.7)$ & 0.008 \\
\hline $\begin{array}{l}\text { C-reactive protein } \\
{[\mathrm{n}=182, \mathrm{IQR}, \mathrm{mg} / \mathrm{L}]}\end{array}$ & $5.8(1.20,32.28)$ & $\begin{array}{l}9.55(2.2,40.23) \\
(n=94)\end{array}$ & $3.5(0.8,15.28)(n=88)$ & 0.001 \\
\hline Serum amyloid $A \geq$ & $82(61.2)$ & $48(61.6)$ & $34(53.1)$ & 0.067 \\
\hline Lactose dehydrogenase $\geq$ & $55(31.8)$ & $34(37.4)$ & $21(25.6)$ & 0.097 \\
\hline $\begin{array}{l}\mathrm{D}-\operatorname{dimer} \geqq 0.5 \\
\mathrm{mg} / \mathrm{L}(\mathrm{n}=171)[\mathrm{n}(\%)]\end{array}$ & $61(35.7)$ & $33(36.3)$ & $28(35.0)$ & 0.863 \\
\hline Fibrinogen [IQR, ug/ml] & $274(216,365)$ & $306(214,386)$ & $247(219,249)(n=89)$ & 0.033 \\
\hline
\end{tabular}

*Lymphopenia denoted the lymphocyte count of less than 1,500 per cubic millimeter.

\#Thrombocytopeniadenoted the platelet count of less than 150,000 per cubic millimeter; ${ }^{\$}$ Neutrophil lymphocyte ratio.

Chest Computed Tomographic Images

We analyzed the chest CT imaging of all 185 patients at the first examination after admission. All data analyzed from CT were divided into four categories: negative, local patchy shadowing, unilateral lobulated shadowing, bilateral patchy shadowing. We performed a $\mathrm{R} \times \mathrm{C}$ chi-square test to compare groups in pairs. Overall, there was no statistical difference between males and females based on CT images, however, higher percentages of CT abnormalities were discovered in male patients $(90.52 \%$ vs78.89\%, $p=.025)$ (Table 4, Fig. 1).

Table 4 Chest Computed Tomographic Images

\begin{tabular}{lllll}
\hline ariables & All Patients (n=185 & Man (n= 95 & Woman (n=90 & P \\
& ) & values \\
\hline ormal [n (\%)] & $28(15.40)$ & $9(9.60)$ & $19(21.60)$ & 0.025 \\
Jcal patchy shadowing [n (\%)] & $24(13.20)$ & $13(13.80)$ & $11(12.50)$ & 0.791 \\
nilateral lobulated shadowing [n & $4(2.20)$ & $1(1.10)$ & $3(3.40)$ & 0.272 \\
o)] & & $71(75.50)$ & $55(62.50)$ & 0.057 \\
lateral patchy shadowing [n (\%)] & $126(69.20)$ & &
\end{tabular}




\section{Severity Assessment And Clinical Complications On Admission}

As described in the diagnostic and treatment guideline for SARS-CoV-2 issued by the Chinese National Health Committee, all patients were divided into general and refractory groups according to the clinical efficacy after hospitalization. By comparing the severity of disease in two groups, the rate of patients diagnosed as general and refractory illness, and refractory patients in the male group was more than that in female group $(p=.014)($ Fig. 2). There is no significant difference between males and females in complications, such as acute respiratory distress syndrome (ARDS), acute kidney insufficiency(AKI) or acute exacerbation of chronic kidney insufficiency, disseminated intravascular coagulation(DIC), acute myocardial injury, co-infection and septic shock $(P>.05)$ (Table 5).

Table 5 Clinical complications and Outcome of Patients Infected on admission

\begin{tabular}{lllll}
\hline ariables & All Patients (n= 185) & Man (n=95) & Woman (n=90 ) & P values \\
\hline RDS [n (\%)] & $18(9.70)$ & $10(10.5)$ & $8(8.9)$ & 0.707 \\
cute renal injury [n (\%)] & $1(0.5)$ & $1(1.1)$ & 0 & $>0.99$ \\
zptic shock[n (\%)] & $4(2.2)$ & $3(3.2)$ & $1(1.1)$ & 0.339 \\
j-infections [n (\%)] & $57(30.8)$ & $32(33.7)$ & $25(27.8)$ & 0.384 \\
yocardial damage [n (\%)] & $6(3.2)$ & $4(4.4)$ & $2(2.1)$ & 0.629 \\
IC [n (\%)] & 0 & 0 & 0 & - \\
two complications [n (\%)] & $61(33.0)$ & $34(35.8)$ & $27(30.0)$ & 0.402 \\
emained in hospital[n (\%)] & $72(38.9)$ & $35(36.8)$ & $37(41.1)$ & 0.552 \\
ecovery [n (\%)] & $96(51.9)$ & $48(50.5)$ & $48(53.3)$ & 0.703 \\
ortality [n (\%)] & $2(1.1)$ & $2(2.1)$ & $0(0)$ & 0.501 \\
eadmission[n (\%)] & $15(8.1)$ & $10(10.5)$ & $5(5.6)$ & 0.216 \\
\hline
\end{tabular}

1: The observation period of this study was from January 13 to March 19, 2020;

2: Discharge criteria 1). Body temperature returns to normal for more than 3 days; 2). Respiratory symptoms improved significantly; 3). Pulmonary imaging showed significant improvement of acute exudative lesions; 4). Two consecutive negative nucleic acid tests of respiratory tract specimens such as sputum, nose and throat swabs (sampling time interval of at least 24 hours);

3: Reason for readmission: Reactivation of SARS-CoV-2 after discharge.

\section{Outcome Of Patients With Covid-19}

As of March 23, 2020, a total of 2 patients died during this period, both of whom were males. The mortality rate of COVID-19 in this study was $1.1 \%$, which did not differ between two groups $(p=.501$, table 7$)$. Furthermore, there was no statistical difference in the number of patients remained in hospital, discharged, re-admitted caused by reactivation of SARS-CoV-2 after discharge $(p>.05)$ (Table 5$)$.

\section{Risk Factor Analysis Of Covid-19 Severity}

Patients were classified in two groups based on severity of COVID-19 as described previously. Correlations between severity of COVID-19 and underlying disease (CHD, HT, T2DM, Respiratory disease, NAFLD) were analyzed in terms of the Spearman correlation coefficient, but weak correlations or no correlation were found with CHD $(p=.007, r=0.196), H T(p<.001, r=0.270), D M(p<.001, r=0.290)$, respiratory disease $(p<.001, r=0.281)$ $\operatorname{NAFLD}(p=.132, r=0.111)$ and disease severity respectively. Due to the limited sample size of coronary heart disease, the data could not be counted accurately and effectively in multivariate regression, only age (analyzed in quartiles, OR: 1.087; 95\% Cl: 1.038-1.139; $p$.001) and BMI (OR: 1.250; 95\% Cl: 1.046-1.493; $p=.014)$ could be used as significant predictors in the multivariate analysis for the severity of disease (Fig. 3). We added spearman correlation analysis between male sex and BMI, and found it to be significant $(p=<.001, r=0.486)$. 


\section{Discussion}

As reported previously, male and female may differ in susceptibility and response to certain infectious diseases. For example, men are more susceptible to certain infectious diseases, such as malaria, SARS, MERS and influenza than females ${ }^{[4,11,12]}$. As known, infectious diseases may cause inflammatory-mediated immune response, and the differences in immune responses between women and men may be related to sex hormones and specific Xchromosome-encoded genes ${ }^{[13]}$. Many previous reports and studies have demonstrated the importance of taken sex difference into consideration during disease research. Taken all the facts into consideration, sex might play a critical role in COVID-19 studies as well. In support of this hypothesis, many existing researches focusing on COVID-19 have reported that there were more male patients admitted than females in the same area, other than that, the mortality and severity rates were also higher in male patients ${ }^{[3,14,15]}$. All previous reports suggested possible sex effects during the progression of COVID-19. In this study, by comparing the baseline data of male and female patients, the mean age and sex ratios of the two groups of patients were similar, which might be limited by geographical factors. However, in male patients, the proportions of smokers (18.9\% vs $2.2 \%)$, patients with coronary heart disease (6.3\% vs $0 \%$ ), patients with NAFLD $(20.00 \%$ vs $8.89 \%)$ were higher than those of female patients. Moreover, more male patients developed symptoms such as high fever, cough and chills. In the related content, the abnormal CT rate in male patients is higher than that in female patient, suggesting the clinical symptoms were more sever and the pulmonary infection progresses faster in male patients. Based upon analyzed data, the refractory illness rate (including critical and severe COVID-19) is higher in the male group than in the female group, which is consistent with the results of recent COVID-19 studies in other regions ${ }^{[16,17]}$.

Many believes that the sex differences of SARS-CoV-2 is related to the difference in ACE2 content in men and women, furthermore, sex is used as a strong indicator of ACE2 concentration ${ }^{[18]}$. ACE2 exists not only in lung, but also in other types of tissue such as heart muscle, kidneys, and blood vessel walls, and is particularly high in testis. It has been reported that SARS-CoV-2 may infect the male genitourinary system, presumably inhibiting the function of cells and reproduction. In support of this, a retrospective study of serum samples collected from 81 male patients with COVID-19 who were admitted to Leishen Mountain Hospital, Wuhan. They found that luteinizing hormone and prolactin levels were significantly increased while testosterone and follicle-stimulating hormone ratios were significantly decreased in patients with COVID-19. This might be caused by damage to the interstitial cells ${ }^{[19]}$. The gene encoding ACE2 is located on the $X$ chromosome. Any $X$ chromosome related diseases generally showed higher infectious rate in males than in females due to the genetic chromosome differences ${ }^{[20,21]}$. As we discovered similar sex differences patterns in COVID-19 disease research, we propose that ACE2 might be related to the sex differences in COVID-19 between males and females as well. Kimberly E. Stelzig demonstrated that estrogen regulates the expression of SARS-CoV-2 receptor ACE2 in differentiated airway

epithelial cells in a single female donor of NHBE cells, however more research is needed to confirm this finding [22]. Other than the genetic contribution, different cultural and behavioral habits might act into the sex differenced in COVID- 9 as well. In this cohort, the percentage of patients who were smokers were significantly higher in male group than that in female group. Long-term smoking might cause underlying lung diseases, which will affect lung ventilation and exacerbate lung disease progression, which played an important part in COVID-19 progressions. Other than that, during the admission process, we found out that men intended to contradict hospital admission and thus were hospitalized longer after onset symptoms observed. This finding suggested that, compared with men, women were more willing and optimistic on seeking medical helps ${ }^{[23]}$. 
Inflammatory storms have been mentioned in many studies, and our study also confirmed the inflammatory response ${ }^{[24]}$. This study indicated that male patients had higher levels of inflammatory markers (including CRP, SAA, FIB), suggesting that bacterial infection is more common in male patients and might aggravate the disease progression $[25,26]$. The elevated AST and CK levels suggested that it may be related to the tissue damage mediated by virus, and the male response is more severe than female. Although the mean platelet counts in males were significantly lower than those in females, the mean platelet counts in both groups were within the normal range, and the thrombocytopenia ratios were parallel between the two groups, therefore, there was no clinical value in the decrease of platelet count between male and female groups. Correlations between severity of COVID19 and underlying disease(CHD, HT, T2DM, Respiratory disease, NAFLD) were analyzed in terms of the Spearman correlation coefficient, but weak correlations or no correlation were found between underlying disease and disease severity respectively. This result is different from previous studies, which may be caused by low proportion of patients with underlying diseases or critically ill patients included in our study. After logistic regression analysis between severe and non-severe cases, we found that age and BMI were independent risk factors, there was a positive correlation between male sex and BMI, which might contribute to the fact that male group had more patients with severe pneumonia and testified the research conclusions of Cai Q and Petrakis D $[27,28]$. Ttorio Emanuele Bianchi conducted a meta-analysis and found that low testosterone levels were associated with high levels of adipocytokines and inflammatory responses. Adipose tissue is a source of many inflammatory factors and may contribute to a more severe inflammatory response in elderly male obese patients ${ }^{[29]}$. In particular, the decrease in testosterone levels in older men and the increase in pro-inflammatory cytokines in obese patients may be particularly pronounced in older obese men, possibly exacerbating COVID-19 progression [30].

There were limitations to the current study. First of all, epidemiological data were collected respectively and recall bias might have occurred. Second, restricted by geographical factors, patients involved in this study were all hospitalized in Beijing Ditan Hospital for treatment, therefore, in this cohort, the sex ratio, clinical manifestation and outcome were different from other regions. We analyzed in-patient mortality as of March 23, with a total of 2 deaths, this is a significant reduction in mortality compared with other regions ${ }^{[3,15]}$. Thirdly, Yang Liu reported that the viral load of SARS-CoV-2 might be a useful marker for assessing disease severity and prognosis ${ }^{[31]}$, however, we did not detect the virus load because of the emergency in progress and limited time availability. We will detect the viral load in the samples which are currently retained in the future, and produce conclusions regarding to the relationship between viral load and disease characteristics and prognosis.

\section{Conclusions}

In this single-center case series of 185 hospitalized patients in Beijing, we found that BMI and age were associated with disease severity even after adjusting for other related potential confounders. Older men with obesity should be given special attention because they were more likely to develop refractory pneumonia. In addition, particular attention should be paid to the relationship between obesity and inflammatory response in male patients. While we recognize these limitations, we hope our study will inspire more researchers to further investigate the effects of sex and obesity on COVID-19.Further research on the underlying mechanism of sexbased differences may provide more basis for the progress of COVID-19 and the study of vaccines or effective drugs.

\section{Abbreviations}


BMI: Body mass index; CHD: coronary heart disease; HT: hypertension ;T2DM:Type 2 diabetes ; NAFLD :nonalcoholic fatty liver disease; ARDS :acute respiratory distress syndrome; AKI: acute kidney injury; DIC: diffuse intravascular coagulation

\section{Declarations}

\section{Acknowledgements}

The authors would like to acknowledge and thank the patients and all the medical staff in Beijing Ditan Hospital, Capital University, and thank Ying Cao for the critical review of a draft of this manuscript

\section{Authors' contributions}

JW, YS and WX conceived and designed the study. JW, QW, and AW extracted information and analyzed the data. JW and YS wrote the manuscript. YC, RD reviewed the manuscript. All authors approved the final manuscript for submissionAll authors read and approved the final manuscript.

\section{Funding}

This research did not receive any specific grant from funding agencies in the public, commercial, or not-for-profit sectors.

\section{Availability of data and materials}

The datasets used and/or analyzed during the current study are available from the corresponding author.

\section{Ethics approval and consent to participate}

This study was reviewed and approved by the Committee for Ethical Affairs of the Beijing Ditan Hospital (DTZZLX-202009).

\section{Consent for publication}

Not applicable.

\section{Competing interests}

The authors declare that there are no conflicts of interest.

\section{Author details}

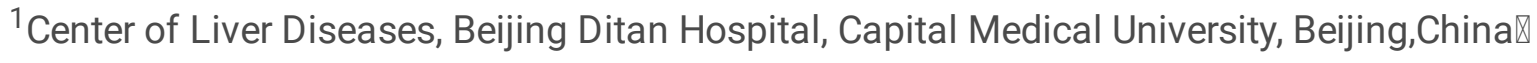

${ }^{2}$ Department of Cardiology, Beijing Ditan Hospital, Capital Medical University, Beijing, China $\bigotimes^{3}$ Infectious Diseases Diagnostic, Therapeutic and Research Centre, Beijing Ditan Hospital, Capital Medical University, Beijing , China

\section{References}


1.Lu R, Zhao X, Li J, et al. Genomic characterisation and epidemiology of 2019 novel coronavirus:implications for virus origins and receptor binding. Lancet. 2020;395(10224):565-574.doi:10.1016/S0140-6736(20)30251-8

2.Zhou P, Yang XL, Wang XG, et al. A pneumonia outbreak associated with a new coronavirus ofprobable bat origin. Nature. 2020;579(7798):270-273. doi:10.1038/s41586-020-2012-7

3.Goel S, Jain T, Hooda A, et al. Clinical Characteristics and In-Hospital Mortality for COVID-19Across The Globe [published online ahead of print, 2020 Jul 18]. Cardiol Ther. 2020;1-7. doi:10.1007/s40119-020-00189-0

4.van Lunzen J, Altfeld M. Sex differences in infectious diseases-common but neglected. J InfectDis. 2014;209 Suppl 3:S79-S80. doi:10.1093/infdis/jiu159

5.Kovats S. Estrogen receptors regulate innate immune cells and signaling pathways. Cell Immunol.2015;294(2):63-69. doi:10.1016/j.cellimm.2015.01.018

6.Jin JM, Bai P, He W, et al. Gender Differences in Patients With COVID-19: Focus on Severity and Mortality. Front Public Health. 2020;8:152. Published 2020 Apr 29. doi:10.3389/fpubh.2020.00152

7.Sharma G, Volgman AS, Michos ED. Sex Differences in Mortality from COVID-19 Pandemic: Are Men Vulnerable and Women Protected? [published online ahead of print, 2020 May 4]. JACC Case Rep. 2020;2(9):1407-1410. doi:10.1016/j.jaccas.2020.04.027

8.Zhang L, Wang Z, Wang X, et al. Prevalence of overweight and obesity in China: Results from across-sectional study of 441 thousand adults, 2012-2015. Obes Res Clin Pract. 2020;14(2):119-126. doi:10.1016/j.orcp.2020.02.005

9.Zhang X, Zhang M, Zhao Z, et al. Geographic Variation in Prevalence of Adult Obesity in China:Results From the 2013-2014 National Chronic Disease and Risk Factor Surveillance. Ann Intern Med. 2020;172(4):291-293. doi:10.7326/M19-0477

10.National health commission, PRC. COVID 19 diagnosis and treatment programme (trial version 7) [EB/OL]. (2020-03-03)[2020-03-04].

http://www.nhc.gov.cn/yzygj/s7653p/202003/46c9 294a7dfe4cef80dc7f5912eb1989.shtml.

11.Karlberg J, Chong DS, Lai WY. Do men have a higher case fatality rate of severe acute respiratorysyndrome than women do?. Am J Epidemiol. 2004;159(3):229-231. doi:10.1093/aje/kwh056

12.Alghamdi IG, Hussain II, Almalki SS, Alghamdi MS, Alghamdi MM, El-Sheemy MA. The patternof Middle East respiratory syndrome coronavirus in Saudi Arabia: a descriptiveepidemiological analysis of data from the Saudi Ministry of Health. Int J Gen Med. 2014;7:417-423. Published 2014 Aug 20. doi:10.2147/IJGM.S67061

13.vom Steeg LG, Klein SL. SeXX Matters in Infectious Disease Pathogenesis. PLoS Pathog.2016;12(2):e1005374. Published 2016 Feb 18. doi:10.1371/journal.ppat.1005374

14.Huang C, Wang Y, Li X, et al. Clinical features of patients infected with 2019 novel coronavirus inWuhan, China [published correction appears in Lancet. 2020 Jan 30;.]. Lancet.2020;395(10223):497-506. doi:10.1016/S01406736(20)30183-5 
15.Wang D, Hu B, Hu C, et al. Clinical Characteristics of 138 Hospitalized Patients With 2019 NovelCoronavirusInfected Pneumonia in Wuhan, China [published online ahead of print, 2020Feb 7]. JAMA. 2020;323(11):10611069. doi:10.1001/jama.2020.1585

16.Guan WJ, Ni ZY, Hu Y, et al. Clinical Characteristics of Coronavirus Disease 2019 in China. NEngl J Med. 2020;382(18):1708-1720. doi:10.1056/NEJMoa2002032

17.Mo P, Xing Y, Xiao Y, et al. Clinical characteristics of refractory COVID-19 pneumonia in Wuhan,China [published online ahead of print, 2020 Mar 16]. Clin Infect Dis. 2020;ciaa270. doi:10.1093/cid/ciaa270

18.Lan J, Ge J, Yu J, et al. Structure of the SARS-CoV-2 spike receptor-binding domain bound to theACE2 receptor. Nature.2020;581(7807):215-220. doi:10.1038/s41586-020-2180-5

19.Ling Ma, Wen Xie Danyang Li, et al . Effect of SARS-CoV-2 infection upon male gonadal function A single center-based study, Preprints with The Lancet .doi:https://doi.org/10.1101/2020.3.21.20037267

20.Kloc M, Ghobrial RM, Kubiak JZ. The Role of Genetic Sex and Mitochondria in Response to COVID-19 Infection [published online ahead of print, 2020 Jun 19]. Int Arch Allergylmmunol. 2020;1-6. doi:10.1159/000508560

21.Culebras E, Hernández F. ACE2 is on the X chromosome: could this explain COVID-19 genderdifferences? [published online ahead of print, 2020 Jun 24]. Eur Heart J. 2020;ehaa521.doi:10.1093/eurheartj/ehaa521

22.Stelzig KE, Canepa-Escaro F, Schiliro M, Berdnikovs S, Prakash YS, Chiarella SE. Estrogenregulates the expression of SARS-CoV-2 receptor ACE2 in differentiated airway epithelialcells. Am J Physiol Lung Cell Mol Physiol. 2020;318(6):L1280-L1281. doi:10.1152/ajplung.00153.202023.Walter LA, McGregor AJ. Sex- and Genderspecific Observations and Implications for COVID-19. West J Emerg Med. 2020;21(3):507-509. Published 2020 Apr 10.doi:10.5811/westjem.2020.4.47536

24.Wei ZY, Qian HY, Huang J, Geng YJ. Pathogenesis and Management of Myocardial Injury in Coronavirus Disease 2019 [published online ahead of print, 2020 Jul 19]. Eur J Heart Fail.2020;10.1002/ejhf.1967. doi:10.1002/ejhf.1967

25.Zhu X, Ge Y, Wu T, et al. Co-infection with respiratory pathogens among COVID-2019cases. Virus Res. 2020;285:198005. doi:10.1016/j.virusres.2020.198005

26.Levi M, Thachil J, Iba T, Levy JH. Coagulation abnormalities and thrombosis in patients withCOVID-19. Lancet Haematol. 2020;7(6):e438-e440. doi:10.1016/S2352-3026(20)30145-9

27.Cai Q, Chen F, Wang T, et al. Obesity and COVID-19 Severity in a Designated Hospital inShenzhen, China. Diabetes Care. 2020;43(7):1392-1398. doi:10.2337/dc20-0576

28.Petrakis D, Margină D, Tsarouhas K, et al. Obesity - a risk factor for increased COVID-19prevalence, severity and lethality (Review). Mol Med Rep. 2020;22(1):9-19. doi:10.3892/mmr.2020.11127

29.Bianchi VE.The Anti-Inflammatory Effects of Testosterone. J Endocr Soc. 2018;3(1):91-107.Published 2018 Oct 22. doi:10.1210/js.2018-00186 
31.Liu Y, Yan LM, Wan L, et al. Viral dynamics in mild and severe cases of COVID-19. Lancet InfectDis. 2020;20(6):656-657. doi:10.1016/S1473-3099(20)30232-2

\section{Figures}

\section{A Chest Computed Tomographic Images of a 36-Year-Old Male Patient Infected With} Infected With SARS-COV-2 by High-Flow Nasal Cannula

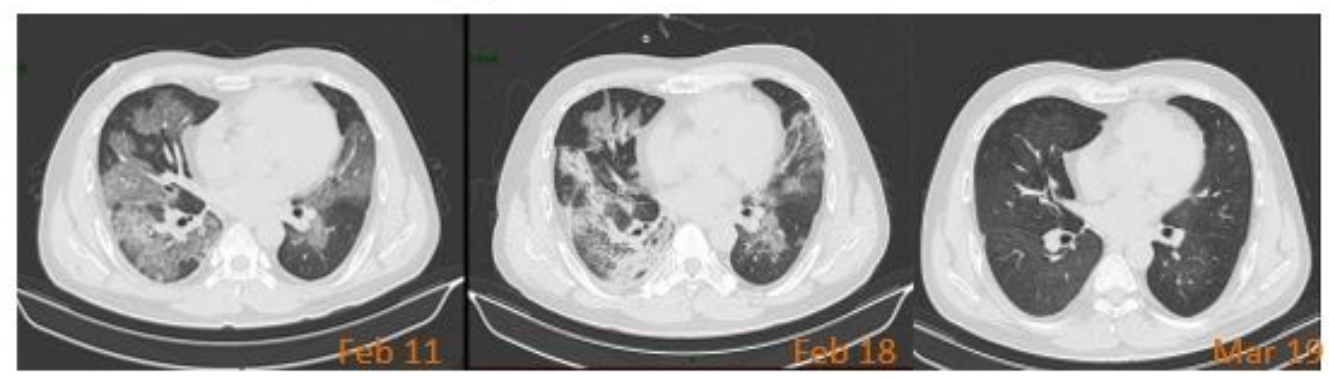

B Chest Computed Tomographic Images of a 78-Year-Old Female Male Patient Infected With SARS-COV-2 by extracorporeal membrane oxygenation

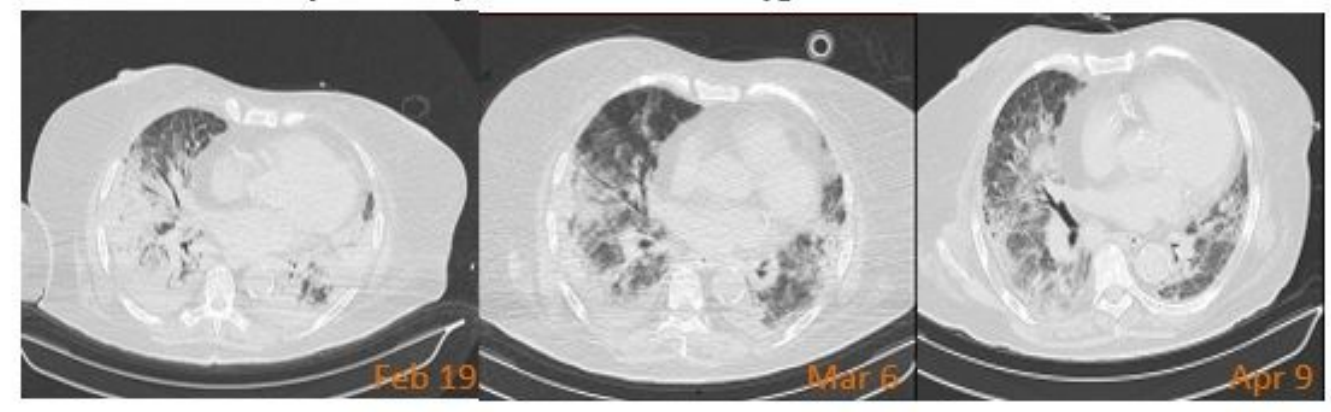

\section{Figure 1}

Chest Computed Tomographic Images of 2 Patients Infected With COVID-19

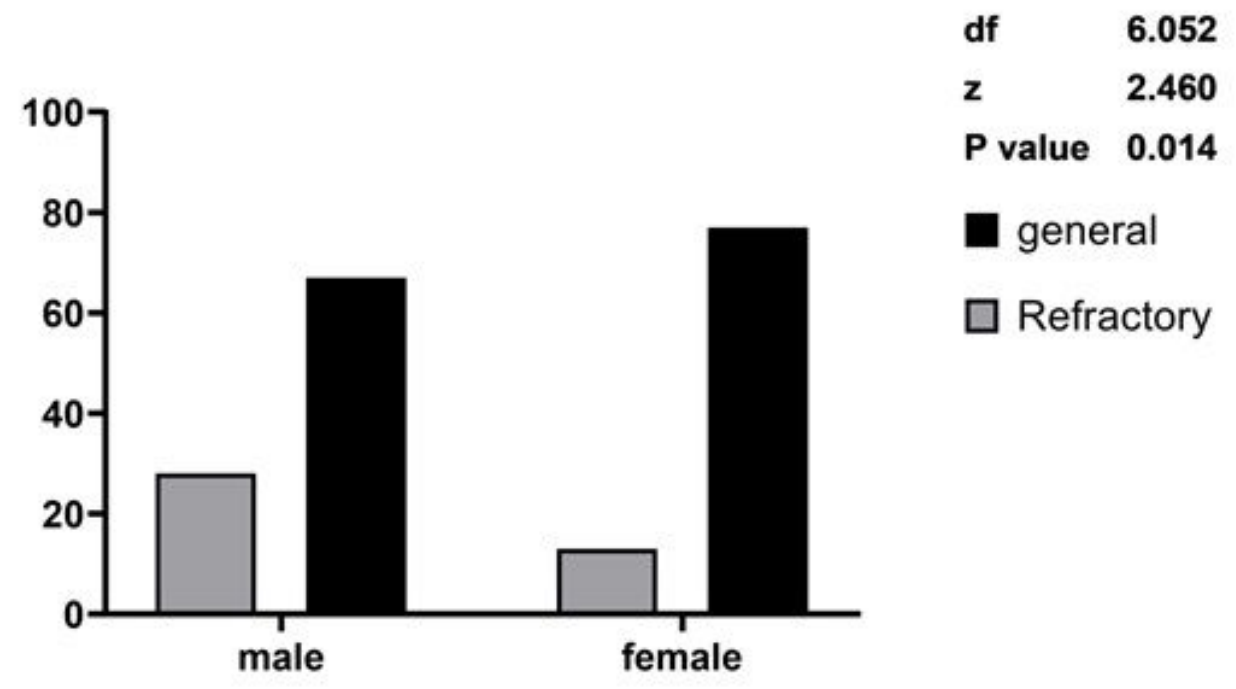


Figure 2

Severity of Patients Infected on admission

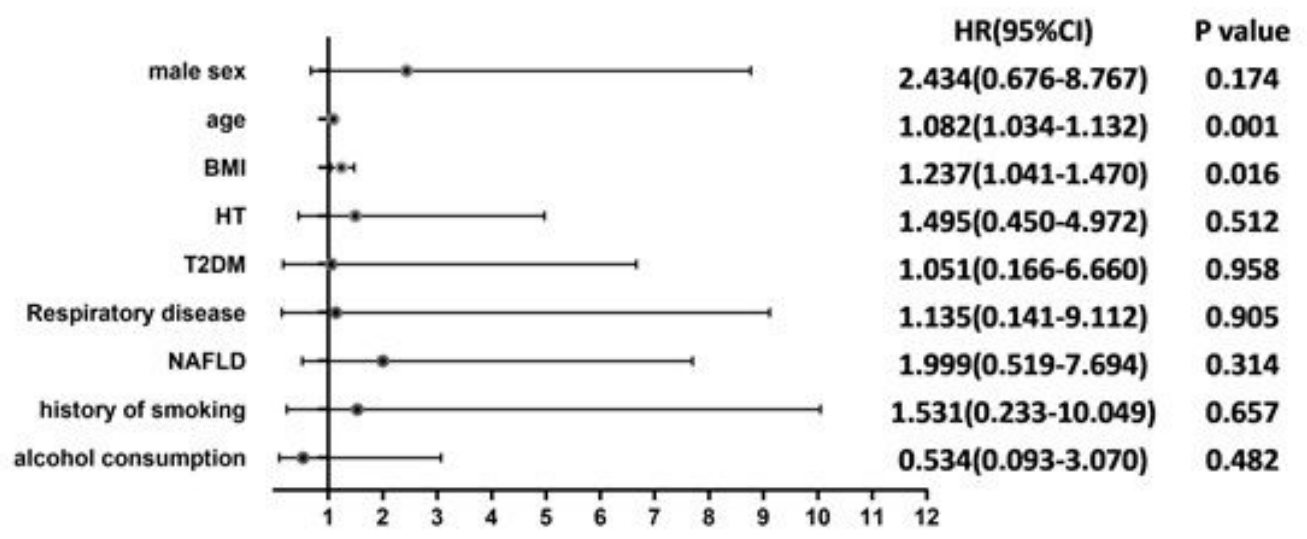

Figure 3

Risk factors for severity of COVID-19 